\title{
O AGENDAMENTO DOS JOGOS RIO 2016: TEMAS E TERMOS PARA DEBATE*
}

\author{
Pedro Athayde \\ Universidade de Brasília, Brasília, Distrito Federal, Brasil \\ Fernando Mascarenhas \\ Universidade de Brasília, Brasília, Distrito Federal, Brasil \\ Wagner Barbosa Matias \\ Universidade de Brasília, Brasília, Distrito Federal, Brasil \\ Natália Nascimento Miranda \\ Universidade de Brasília, Brasília, Distrito Federal, Brasil
}

\section{Resumo}

A formação da agenda compreende um momento decisivo na formulação de políticas públicas, delimitando objetos de intervenção governamental. Neste sentido, buscamos analisar os temas e termos que perpassam o agendamento dos Jogos Rio 2016. A pesquisa se baseou em levantamento documental construído a partir de fontes institucionais e mídia impressa, discutidos com apoio na técnica de análise de conteúdo. Permitiu mapear os interesses que perpassaram a candidatura carioca a sede dos Jogos Olímpicos, identificar as tendências da política esportiva brasileira e discutir a relação público-privado no contexto de organização dos Jogos, bem como apontar desafios para a agenda de pesquisas sobre megaeventos esportivos.

Palavras-chave: Políticas públicas. Parceria Público-Privada. Esportes.

\section{Introdução}

\begin{abstract}
A s políticas esportivas no Brasil, desde a realização dos Jogos A Pan-Americanos de 2007 e a postulação da cidade do Rio de Janeiro a sede dos Jogos Olímpicos e Paraolímpicos de 2016, oficializada ainda naquele ano, têm sido influenciadas pelo objetivo de projetar o país, tanto no esporte, como na área política e econômica. Em junho de 2008, confirmada pelo Comitê Olímpico Internacional (COI) como candidata, a capital carioca pela primeira vez chegou à fase final do processo de escolha da sede olímpica. Desta vez, malgrado a precoce eliminação na primeira etapa da disputa para os Jogos de 2004 e 2012, o apoio governamental, afiançando os investimentos necessários, e a posição brasileira no cenário internacional foram decisivos. Assim, após votação realizada na $121^{\text {a }}$ Sessão do COI no dia 2 de outubro de
\end{abstract}

* O presente trabalho foi realizado com apoio do CNPq, Conselho Nacional de Desenvolvimento Científico e Tecnológico - Brasil

Pensar a Prática, Goiânia, v. 16, n. 3, p. 619-955, jul./set. 2013

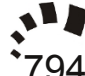


2009 em Copenhague, o projeto Rio 2016 foi anunciado vitorioso, derrotando as candidaturas de Chicago, Tóquio e Madri.

O Brasil sediará ainda a Copa do Mundo FIFA de 2014. No entanto, para os fins desta investigação, delimitaremos nossa análise, circunscrevendo-a ao projeto olímpico. Buscaremos compreender como este projeto foi pautado no âmbito do Estado, da mídia e da própria organização esportiva, constituindo-se como princípio organizador da agenda esportiva do país. A formação da agenda compreende um momento decisivo na formulação de políticas públicas, caracterizando-se como um processo em que determinados temas emergem, delimitando um objeto de intervenção governamental. Ocorre que este processo envolve diferentes visões e interesses, mobilizando atores específicos da sociedade e do Estado, que fundamentam suas argumentações no sentido de regulamentar e influenciar ações que conferem materialidade à política. Neste sentido, nosso objeto de investigação envolve a análise dos temas e termos que perpassaram o agendamento dos Jogos Rio 2016.

\section{Delineamento do estudo}

Este estudo pode ser caracterizado como uma pesquisa de caráter qualitativo que se apoiou em levantamento documental construído a partir de fontes institucionais e material produzido pela mídia impressa. As seguintes fontes institucionais foram pesquisadas: (i) notícias publicadas pela Assessoria de Comunicação do Ministério do Esporte (ME); (ii) documentos da III Conferência Nacional do Esporte; (iii) portal eletrônico do COI; (iv) portal eletrônico do Comitê Olímpico Brasileiro (COB); (v) portal eletrônico dos Jogos Rio 2016; e, (vi) Dossiê de Candidatura (COMITÊ RIO 2016, 2009). No que corresponde à mídia impressa, utilizou-se como fonte exclusiva o acervo do jornal Folha de S. Paulo (FSP). Dado o objeto proposto para a investigação, registramos que tal busca foi realizada nos marcos de um recorte correspondente ao período de $1^{\circ}$ de setembro de 2006 a 29 de julho de 2010, isto é, desde a Assembleia Geral do COB que definiu o Rio de Janeiro como cidade postulante a sede olímpica até a data de divulgação do Host City Contract.

Juntos, comunicação e documentos governamentais, dados das entidades de administração do esporte olímpico, do comitê organizador e produção midiática, bem como o próprio projeto institucional dos 
Jogos, fornecem um expressivo material para a codificação da agenda. Quanto à base operacional e técnica para o tratamento deste material, com a pretensão de se alcançar o significado das informações, enunciados e termos expressos pelos documentos, inferindo as visões e concepções presentes, foi utilizado o método de análise de conteúdo (BARDIN, 2010; FRANCO, 2005). Assim, a atividade de pré-análise, realizada a partir da leitura flutuante de todo material, permitiu a definição de um corpus de análise constituído por 875 registros da FSP e 162 do $\mathrm{ME}^{1}$, além de informações dos portais e documentos citados, estes últimos, não tabulados e quantificados, mas utilizados como recurso da investigação.

Considerando a frequência dos temas observados, o conjunto destes registros foi agrupado em unidades temáticas, conforme Tabela 1.

Tabela 1: Distribuição do registro de notícias agrupadas por Unidade Temática

\begin{tabular}{lr}
\hline Unidades & Registros \\
\hline Política esportiva & 341 \\
\hline Jogos Pan-Americanos de 2007 & 112 \\
\hline Rio cidade candidata & 100 \\
Projeto Rio 2016 & 88 \\
Financiamento & 85 \\
Concorrência interurbana & 75 \\
Governança urbana & 48 \\
Opinião pública & 41 \\
Movimento Olímpico & 35 \\
Equipamentos esportivos & 34 \\
Segurança pública & 26 \\
Infraestrutura urbana & 25 \\
Propriedade intelectual e direitos de imagem & 16 \\
Turismo & 11 \\
Total & $\mathbf{1 . 0 3 7}$ \\
\hline
\end{tabular}

A análise propriamente dita, que envolveu a exaustiva leitura de todo o material, esteve apoiada em um quadro teórico construído a partir de revisão de literatura sobre Políticas Públicas, Políticas Esportivas e Estudos Olímpicos, cujas principais referências serão apresentadas ao longo do texto. Partindo dessa organização, bem como de constantes idas e vindas da teoria ao material de análise, passamos a discussão e aos resultados da investigação, cujos recortes de exposi-

1-Conforme busca operada pelos descritores "Jogos", "Olimpíadas" e "Rio 2016", foram selecionados inicialmente 1.685 registros a partir do portal da FSP e 200 registros do ME. Entretanto, após a leitura flutuante, parte destes registros foi desprezada por não se relacionar diretamente ao tema pesquisado. 
ção a serem apresentados foram organizados a partir dos temas privilegiados na configuração da agenda Rio $2016^{2}$.

\section{Política esportiva}

Esta é a unidade temática que apresenta maior ocorrência de registros, o que se deve à amplitude da categorização adotada. De todo modo, há grande identificação entre o material selecionado, ainda que reunindo notícias sobre variados aspectos do desenvolvimento esportivo, envolvendo desde a estrutura e organização necessária ao seu incremento até questões mais elementares de seu cotidiano. $\mathrm{O}$ que chama atenção é que os registros que compõem esta unidade são reveladores do impacto que os Jogos de 2016 já exercem no cenário esportivo nacional.

No tocante à agenda pública, o tema do desenvolvimento esportivo se expressa pela formulação de novas políticas através da III Conferência Nacional do Esporte (CNE), realizada no primeiro semestre de 2010. A III CNE apresentou para discussão o "Plano Decenal de Esporte e Lazer" que, subordinado ao slogan "Por um time chamado Brasil", foi construído a partir de metas e ações em torno de "10 pontos em 10 anos para projetar o Brasil entre os 10 mais" (BRASIL, 2010).

O principal objetivo do Plano Decenal de Esporte e Lazer é a projeção do Brasil como potência esportiva mundial. A meta é:

Ficar entre os 10 melhores colocados nas olimpíadas 2016 e entre os 5 melhores colocados nas paraolimpíadas 2016, e entre os 50 melhores nas surdo-olimpíadas 2013 e 2017; ficar entre os 03 melhores colocados nos Jogos Panamericanos de 2011 e entre os 02 melhores em 2015 e ficar entre os 5 melhores nos jogos Pan-americanos de surdos 2011 e 2015, avaliando os resultados para novas metas para as próximas olimpíadas e paraolimpíadas através da implantação de uma política pública que priorize e fomente o esporte, o paradesporto e o desporto de surdo de rendimento no âmbito municipal, regional, estadual e

2-Diante do quantitativo de registros e dos limites de extensão impostos para a construção deste texto-relatório da pesquisa, discutiremos em separado e em maior profundidade as cinco unidades temáticas cujos registros foram mais recorrentes. 
nacional, desenvolvendo a prática de um maior número de modalidades esportivas e paradesportivas e de desporto de surdo nos estados e municípios (BRASIL, 2010b, p. 1).

Desenvolver o esporte significa desenvolver o esporte de rendimento. A aspiração brasileira a um posto melhor no ranking de medalhas olímpicas, alçando o país à condição de potência olímpica impacta também no trabalho e planejamento das entidades de administração do esporte. Vejamos o exemplo do tênis:

Depois de um ano participando da reestruturação da CBT (Confederação Brasileira da Tênis), o coordenador da entidade, o espanhol Emilio Sánchez, apresentou ontem metas para o esporte no país. Para 2016, o objetivo é ter oito jogadores (quatro homens e quatro mulheres) no top 40. "Isso é para a gente ter chances não apenas de participar dos Jogos [Olímpicos do Rio de Janeiro, em 2016] mas também de ganhar medalhas", disse Sánchez, ex-capitão da Espanha, campeã da Davis em 2008 (ITOKAZU, 2010, n.p.).

O que se percebe é uma visão de que para o desenvolvimento esportivo nacional é imperioso o melhor desempenho de seus atletas no esporte de rendimento, associação presente tanto agenda pública como no agendamento midiático do esporte. Assim, esta dimensão do esporte - isto é, o esporte de rendimento -, acaba por subordinar o esporte educacional ou escolar. Não por acaso, outra ação do Plano Decenal de Esporte e Lazer aponta para a "criação de uma estrutura política esportiva padronizada desde as escolas até os centros de excelência (...) [com a meta de] integração entre Esporte e Educação, em todos os níveis de governo, para que a formação esportiva seja obrigatória”. (BRASIL, 2010b, n. p.) Por sua vez, fora do ambiente escolar, quando se trata de esporte de participação ou comunitário, a orientação para os projetos sociais não é diferente.

Com o objetivo de descobrir novos talentos olímpicos no judô, natação e atletismo, a multinacional brasileira Vale lançou no Complexo esportivo de Deodoro, no Rio de Janeiro, a Pedra Fundamental da Estação Conhecimento Vila Militar e o programa Brasil Vale Ouro, por meio de uma parceria com os mi- 
nistérios do Esporte e da Defesa. Além de ter uma unidade que atenderá cerca de duas mil crianças do Rio de Janeiro, a Vila Militar de Deodoro vai abrigar o Centro Nacional de Excelência do Brasil Vale Ouro, em que serão transferidos todos os atletas das unidades regionais que obtiverem índice olímpico das três modalidades (BRASIL, 2009, n.p.).

O desenvolvimento esportivo pela via da massificação do chamado esporte de base não é um caminho novo. De acordo com Bracht e Almeida (2003), tal perspectiva se revitaliza a cada novo ciclo olímpico. Seja a partir da ação governamental, de parcerias público-privadas ou de empreendimentos do terceiro setor, o que se verifica é o mais do mesmo. Retomam a antiga ideia da pirâmide esportiva.

Parte-se da premissa que a ampliação da prática esportiva fará surgir novos talentos e com isso o país poderá obter melhores resultados esportivos, além de promover a ascensão social desses jovens. Contudo não se considera que as condições de profissionalização e o surgimento de grandes talentos esportivos em massa, não só nos esportes mais divulgados, passam não somente pela oferta das modalidades - relevante, mas não suficiente - mas também pela mudança nas condições de vida da população (MELO, 2005, p. 78).

A massificação é, aliás, a perspectiva também presente no Dossiê de Candidatura dos Jogos Rio 2016, que fixa a meta de ampliação do Programa Segundo Tempo, com o atendimento saltando de 1 milhão para 3 milhões de jovens, o investimento de 400 milhões de dólares no Programa Mais Educação e a duplicação do número de participantes nos Jogos Escolares Brasileiros (JEB's) e Jogos Universitários Brasileiros (JUB's) (COMITÊ RIO 2016, 2009). Mas se é a massificação que confere o tom do debate em torno do desenvolvimento esportivo nacional, o que significa ampliar o financiamento do número de atletas no esporte de base, vale assinalar que novas propostas são aventadas, ainda que igualmente voltadas ao melhor posicionamento do país no ranking de medalhas olímpicas.

Exemplo disso é que, frequentemente questionado quanto à sua estratégia e planejamento, bem como pelo volume de recursos de que dispõe, o COB passa a ser pautado a partir da difusão de outros mo- 
delos de desenvolvimento esportivo - diga-se, desenvolvimento olímpico -, como por exemplo, o modelo canadense.

Apesar de ter metas ousadas, o programa "Own the Podium" tem um orçamento muito baixo se comparado às cifras despejadas no esporte brasileiro. No ciclo olímpico anterior aos Jogos de Pequim-08, o programa canadense gastou R \$ 111 milhões em modalidades de verão, enquanto o COB recebeu no mesmo período mais que o dobro da Lei Piva -foram cerca de $\mathrm{R} \$ 270$ milhões. Na China, o Canadá ficou em $19^{\circ}$ lugar, com 18 medalhas, enquanto o Brasil foi o $23^{\circ}$, com 15 pódios. O investimento canadense também foi feito de acordo com o número de medalhas que cada modalidade distribui e com a qualidade dos praticantes. Um dos esportes mais tradicionais do país, o hóquei ganhou menos ( $\mathrm{R} \$ 4,6$ milhões) do que o esqui alpino ( $\mathrm{R} \$ 6,1$ milhões), que distribui mais ouros -10 contra 2 do hóquei. No Brasil, só é levado em conta a performance em cada modalidade. O vôlei, por exemplo, distribui só quatro ouros olímpicos e recebeu $\mathrm{R} \$ 2,5$ milhões da Lei Piva. Já as lutas, que oferecem 18 ouros, ganharam R\$ 900 mil (FOLHA DE S. PAULO, 2010, n.p.).

A alternativa do $\mathrm{COB}$ foi proposta pelo Programa Time Brasil, cuja estratégia se define a partir de três eixos, a saber: o primeiro consiste em aumentar o número de medalhas nos esportes que já são medalhistas - exemplo do vôlei, basquete, futebol, atletismo, natação, judô, vela e hipismo; o segundo é o de focalizar um esporte que tenha o potencial de conquistar várias medalhas - exemplo do judô; e, o terceiro é aumentar o número de modalidades em que o Brasil tenha possibilidade de pódio. Quiçá, o grande diferencial do projeto esteja no estímulo a essas novas modalidades esportivas, ampliando o acesso e criando estruturas para os seus praticantes. No entanto, como o interesse que prevalece é ampliação do número de medalhas, o pragmatismo pode se materializar na ausência de continuidade na promoção dessas modalidades caso seus atletas frustrem a expectativa gerada. 


\section{Jogos Pan-americanos de 2007}

Os Jogos Pan-americanos de 2007 marcam uma virada nas políticas esportivas brasileiras. Foi após sua realização que os megaeventos esportivos e, particularmente, a candidatura do Rio de Janeiro a sede olímpica, passaram a ocupar lugar de destaque na agenda pública nacional. Ainda que o COB já tivesse postulado a vinda dos Jogos Olímpicos para o Rio em 2004 e 2012, foi em função do Pan de 2007 que a pretensão da entidade ganhou força, pois, com o envolvimento do governo federal, foram criadas as condições para a conformação de uma ampla coalizão de forças cujas pretensões e interesses repercutiram como a própria vontade geral, isto é, o interesse geral de toda a sociedade ou nação (MASCARENHAS et al., 2011).

Não por acaso, ao analisar o conjunto dos registros envolvendo o tema, tanto o COB como as autoridades dos governos municipal, estadual e federal são unívocos ao afirmarem o sucesso do Pan de 2007.

A experiência do Rio em termos de grandes eventos e de legado, tanto no plano material quanto no intelectual, garantirá uma excelente entrega dos Jogos. Mais de US\$ 2 bilhões foram investidos em infraestrutura e nas instalações dos Jogos Panamericanos e Parapan-americanos Rio 2007, que foram um sucesso, fornecendo assim grande parte dos fundamentos para o projeto Rio 2016. Os Jogos Rio 2007 também testemunharam níveis inéditos de colaboração e união entre o Governo Federal e as autoridades municipais e estaduais, cada um fornecendo o nível de compromisso e cooperação necessários (COMITÊ RIO 2016, 2009).

A avaliação, portanto, é que o legado dos Jogos Pan-americanos, além de infraestrutura e instalações esportivas, envolveu também o know-how adquirido para a preparação da candidatura do Rio de Janeiro a sede dos Jogos Olímpicos de 2016. Ao falarmos em legados do Pan, faz-se indispensável uma apreciação crítica sobre o seu significado. Villano e Terra (2008), afirmam que não existe uma definição clara para os legados de megaeventos esportivos. De acordo com os autores, trata-se de um conceito complexo e polissêmico, que pode inclusive ser melhor traduzido por outros termos e idiomas, expres- 
sando seu caráter histórico e perspectiva de continuidade. De todo modo, há o entendimento de que os legados se constituem como uma herança positiva e duradoura.

A aquisição de conhecimento e experiência por parte do $\mathrm{COB}$ e entes governamentais no tocante à organização de megaeventos esportivos a partir da organização do Pan 2007 é inconteste. Do mesmo modo, é verdade que o evento legou uma infraestrutura esportiva expressiva para a cidade, podendo ampliar do acesso da população à prática esportiva e impulsionar o desenvolvimento do esporte de alto rendimento no país. No entanto, os dirigentes esportivos e autoridades públicas parecem ignorar os problemas que envolveram seu planejamento e realização, o que pode ser considerado como parte da estratégia de legitimação do projeto olímpico.

O recorte de nossa pesquisa abrangeu o período de realização do Pan 2007, por isso obtivemos um grande quantitativo de registros referentes a este tema. Contudo, a partir da leitura flutuante, buscamos selecionar aquelas notícias que traziam vinculação direta com a agenda Rio 2016. E a maior parte delas se refere à herança negativa do evento, sobretudo, denúncias de irregularidades. Em junho de 2009, o Tribunal de Contas da União (TCU) divulgou relatório apontando uma série de irregularidades na organização do evento, com destaque para o não cumprimento de metas pré-estabelecidas e o superfaturamento de alguns processos licitatórios. Soma-se a isto o aumento dos gastos para sua realização. O Pan teve seu custo inicial estimado em R\$ 410 milhões, em 2002. Em outubro de 2006, já somavam R $\$ 2,8$ bilhões. Em março e junho de 2007, os valores cresceram ainda mais: $\mathrm{R} \$ 3,2$ bilhões e $\mathrm{R} \$ 3,7$ bilhões. Ao fim, o crescimento do gasto foi de $793 \%$ em relação à projeção inicial.

Irregularidades e um planejamento questionável marcaram a organização do Pan de 2007. No entanto, para Preuss (2008), o sucesso de um projeto desta magnitude não pode ser avaliado à luz da previsibilidade e exatidão. A imprecisão do orçamento de megaeventos não constitui propriamente um problema, pois sua organização deve ser orientada a partir dos interesses e das expectativas dos diversos segmentos envolvidos, públicos e privados. Para este especialista em economia do esporte, o que deve ser bem planejado é o legado, a fim de não tornar os projetos dispendiosos. Não há, portanto, preocupação retórica alguma de esconder a essência da operação. "No lugar do planejamento moderno, compreensivo, marcado por uma ação direti- 
va do Estado, um planejamento dito estratégico, que se pretende flexível, orientado pelo e para o mercado" (VAINER, 2009, p. 4).

\section{Rio cidade candidata}

Embora a Assembleia Geral do COB que definiu o Rio de Janeiro como postulante a sede olímpica tenha ocorrido em $1^{\circ}$ de setembro de 2006, a cidade foi confirmada oficialmente como candidata em 4 de junho de 2008 e, em 02 de outubro de 2009 foi eleita a cidade sede em 2016. Assim, como nosso recorte abrange todo processo de candidatura, há um significativo número de registros sobre a ações e estratégias do Comitê Rio 2016 e concorrentes, além de relatos sobre as fases da disputa e os procedimentos adotados pelo COI para subsidiar sua decisão.

Lanterna na primeira avaliação da corrida à Olimpíada de 2016, há mais de um ano, o Rio de Janeiro igualou-se ontem aos concorrentes no segundo e definitivo relatório do COI (Comitê Olímpico Internacional). A entidade escolherá a sede em Copenhague (Dinamarca), em 2 outubro. Também concorrem Chicago (EUA), Madri (Espanha) e Tóquio (Japão). [...]. O COI classificou o dossiê do Rio-2016 como de "alta qualidade". O documento de Madri foi criticado: não deixou claro quem financia cada projeto (FOLHA DE S. PAULO, 2009b, n.p.).

No entanto, mais do que informes sobre o processo de disputa, o tema da candidatura olímpica sugere também uma discussão sobre os motivos que justificam, por parte de diferentes cidades e nações, a mobilização de um significativo volume de recursos e pessoal na tentativa de conquistar o direito de sediar os Jogos Olímpicos. De acordo com Tavares (2005), três campos de interesse envolvem tamanha concorrência, a saber: as relações internacionais, os aspectos psicológicos e a demonstração de mudanças.

Devido a sua dimensão global, os Jogos Olímpicos constituem-se como uma oportunidade para a projeção internacional do país sede. No caso do Brasil, os Jogos Rio 2016 corroboram com as ambições do país de exercer maior liderança política e econômica. Nesse sentido, observamos que tal perspectiva alinha-se à diplomacia do governo 
Lula, caracterizada por Almeida (2004) a partir da estratégia de se fazer ouvir nas decisões em torno dos grandes problemas da comunidade internacional, proclamando uma maior presença do Brasil no mundo, alçando-o à condição de potência e autêntico global player.

O auge foi o Cristo Redentor decolando na capa da "Economist", bíblia liberal do jornalismo, logo depois de o Rio ser escolhido, em outubro, sede da Olimpíada de 2016. Mas teve também, entre paparicos incontáveis às vezes levados a sério demais, "o cara" Luiz Inácio Lula da Silva saudado por um Barack Obama fresco da urna, na reunião do G20 em abril; Lula como "personagem do ano" de "El País"; e os aplausos ao Brasil na conferência do clima (ANTUNES, 2009, n. p.).

Em relação aos aspectos psicológicos, Tavares (2005) destaca a possibilidade de que os Jogos, além de reforçar o sentimento de identidade e unidade nacional, contribuem com autoestima da população local. Não por acaso, logo após a escolha do Rio, Lula comemorou: "Deixamos de ser um país de segunda classe. Ganhamos a cidadania internacional". Quanto à opinião pública, segundo consta do Dossiê de Candidatura, 78\% dos cariocas apoiavam a realização dos Jogos, enquanto $46 \%$ dos jovens entre 16 e 24 anos manifestaram o desejo de ser voluntários (COMITÊ RIO 2016, 2009). Tais dados reforçam, portanto, a construção de um consenso simbólico-cultural em torno dos benefícios trazidos pelos Jogos, reforçado, sobretudo, pelo sentimento de orgulho nacional despertado.

Por fim, a demonstração de mudanças está ligada tanto ao ambiente interno como à dimensão das relações internacionais. A escolha como sede olímpica atrai os holofotes da mídia internacional para o país, fornecendo um cenário propício para que demonstre seus avanços e transformações. Tavares (2005) cita como exemplos as edições dos Jogos Olímpicos de Munique em 1972 e de Barcelona 1992, onde os países buscavam demonstrar, respectivamente, que haviam superado a orientação política nazista e franquista. Os registros ainda não permitem inferir a mensagem brasileira, pois vejamos a avaliação do ministro do Esporte, Orlando Silva:

A Copa e a Olimpíada são duas grandes plataformas de promoção. Então o novo Brasil vai aparecer para o mundo, com a Co- 
pa e a Olimpíada. O Lula já ocupa um espaço importantíssimo pela sua liderança e carisma. Mas essa agenda, tenho certeza, vai elevar o patamar de projeção do país. Talvez seja a plataforma de lançamento do Brasil para o século 21 (MARTINS, 2009, n.p.).

O fato é que, para além do impulso ao desenvolvimento da economia local, as inovações prometidas ou pretendidas a partir dos Jogos guardam o potencial de fixarem uma imagem socialmente atraente para o Rio de Janeiro, a imagem de uma cidade adaptada à finalidade competitiva, apta a receber novos fluxos de investimentos, de produção e consumo. Os Jogos e demais megaeventos estão ligados a uma revolução no sistema urbano, a uma nova modalidade do planejamento e ordenamento territorial, fazendo da cidade uma espécie de empresa que concorre no mercado com outras cidades empresa (HARVEY, 2006; VAINER, 2009; 2010).

\section{Projeto Rio 2016}

O tema do Projeto Rio 2016 é bastante abrangente, tangenciando todas as demais temáticas. Ainda que mantenha continuidade em relação ao tema anterior, articula-se menos aos elementos justificadores da candidatura e mais à preparação e construção do projeto Rio 2016. Portanto, os registros reunidos nesta unidade se reportam a aspectos mais técnicos do planejamento realizado, a saber: os agentes envolvidos na gestão das ações da candidatura e organização dos Jogos, a própria preparação do Dossiê de Candidatura, a estratégia e os recursos de marketing mobilizados na campanha, os cuidados contratuais, os parceiros econômicos e futuros investidores, os mecanismos de transparência anunciados, dentre outros.

$\mathrm{Na}$ fase que antecede a candidatura, quando o Rio de Janeiro era ainda postulante, a gestão do projeto apresentou-se como um momento de averiguação sistemática acerca das condições elementares e necessárias aos locais indicado para a realização do megaevento esportivo. Transcorrida esta primeira fase, tiverem início um conjunto de ações voltadas à elaboração de projetos e documentos imprescindíveis à oficialização da candidatura. A confecção desses documentos, que ganharam forma final através do Dossiê de Candidatura foi prota- 
gonizada por agentes e instituições de governo, em especial, do governo federal.

Integrantes do Comitê de Gestão das Ações Governamentais para a Candidatura Rio 2016 estiveram reunidos nesta quartafeira (10) em Brasília para reafirmar o apoio da União à Candidatura do Rio de Janeiro para sediar os Jogos Olímpicos e Paraolímpicos de 2016. Durante o encontro, 27 representantes de Ministérios e órgãos federais, além de dirigentes do Comitê Olímpico Brasileiro, compartilharam os objetivos da candidatura e analisaram as garantias que o Brasil precisa oferecer para sacramentar a confiança do Comitê Olímpico Internacional (COI) na capacidade de o País realizar os dois eventos (BRASIL, 2008, n.p.).

Uma vez confirmada a cidade do Rio de Janeiro como sede olímpica, o comitê de candidatura deu lugar a criação de dois novos entes, o Comitê Organizador dos Jogos Olímpicos (COJO) e a Autoridade Pública Olímpica (APO). O primeiro, sob controle do COB, será responsável pelo planejamento operacional e pela realização dos Jogos, gerenciando inclusive a receita e as despesas operacionais do evento.

Se os Jogos Rio 2016 der prejuízo, os cofres públicos devem cobrir o buraco. Se der lucro, $80 \%$ do dinheiro ficará nas mãos do presidente do COB e do COJO. É o que foi estabelecido pelo estatuto do Rio 2016, já aprovado pelas confederações. O documento determina que $20 \%$ do lucro será dado ao COB e outros $20 \%$ serão devolvidos ao COI. Nuzman fará uma proposta para o uso dos outros $60 \%$ para a diretoria do COJO. Pelo estatuto, essa diretoria será composta por Nuzman e cinco vicepresidentes. Um deles será o secretário-geral do $\mathrm{COB}$, cujo Conselho Executivo indica os outros quatro vices. Há membros do governo no Conselho do COJO. São três representantes, um de cada nível. Mas Nuzman tem quatro integrantes aliados nesse organismo. Ou seja, na prática, ele terá o controle sobre a cúpula do comitê organizador (MATTOS, 2010, n.p.).

Já a APO é um consórcio dos governos municipal, estadual e federal destinado à coordenação e entrega dos investimentos, projetos e 
ações governamentais. Sua criação se deu por exigência do COI a fim de facilitar sua fiscalização sobre o cumprimento dos acordos firmados. É prática do comitê internacional participar da execução do projeto olímpico, impondo seu próprio plano geral de organização. Isto porque a evolução do marketing esportivo transformou os Jogos num megaevento empresarial, enormemente lucrativo e totalmente inserido na economia política global.

Ao longo do século XX, a difusão de hábitos esportivos e a conformação de uma cultura de massa levaram à expansão do consumo de artefatos, equipamentos e serviços relacionados à prática esportiva, assim como transformaram os principais eventos esportivos em espetáculos altamente veiculados pela mass media. Em consequência, o esporte-espetáculo tornou-se nas últimas décadas um dos "veículos de comunicação" mais utilizados pelo mundo empresarial para difundir produtos e consolidar marcas mundiais. Esse é o contexto no qual devemos compreender a evolução do marketing esportivo e sua influência sobre a organização de torneios (PRONI, 1998, p.83).

Diante da mercantilização e espetacularização crescentes, o marketing esportivo ressignificou o próprio processo das candidaturas olímpicas. Os documentos e outros materiais de campanha produzidos pelas cidades candidatas foram transformados em grandes obras publicitárias, onde muitas vezes os elementos de apelo emocional, de caráter ficcional e de conteúdo dramatúrgico preponderam em relação a aspectos técnicos e operacionais. Capitaneada por executivo americano Scott Givens, ex-vice-presidente de entretenimento da Disney, a apresentação brasileira na sessão do COI que definiu a cidade sede, com vídeo assinado por Fernando Meirelles, é um exemplo de espetacularização do projeto olímpico ${ }^{3}$.

Os elementos de marketing mobilizados a partir do projeto olímpico funcionaram tanto para fortalecer competitivamente a candidatura como serviram de instrumento político para legitimação e construção de consensos e orgulho cívico em torno do projeto. Ocorre que os Jo-

3-"[O Brasil] fez uma apresentação fantástica, emocional, gostei muito", disse o campeão olímpico de salto com vara Sergei Bubka, votante do COI ( FOLHA DE S. PAULO, 2009c, n. p.). 
gos Olímpicos, ainda que tenham no espetáculo esportivo e na ideia de união o seu valor aparente, que é justamente o que o marketing e a propaganda buscam evidenciar, tornaram-se, conforme aponta Vainer (2010), um verdadeiro balcão de negócios, combinando variadas estratégias de acumulação.

Neste contexto, no conjunto de registros referentes à construção do projeto olímpico carioca, chamam atenção duas tendências. A primeira, já apontada, é relativa à preocupação do $\mathrm{COI}$ em manter o controle da execução do projeto e plano de organização dos Jogos, o que se justifica diante da lucratividade do evento. Na conta dos dividendos além da venda de ingressos e espaços de publicidade, devem ser somados os direitos de imagem e licenciamento de produtos. A segunda tendência relaciona-se, justamente, às garantias governamentais - Ato Olímpico e Host City Contract - que asseguram o monopólio sobre os negócios envolvendo os Jogos. Como explica Harvey (2006), os megaeventos foram transformados em commodities, tipos especiais de mercadorias culturais que possuem cotação e negociabilidade globais. Assim, a singularidade e particularidade dos Jogos, identificado aqui como commodities, garante ao COI o poder monopolista e vantagem de negociação com os Estados nacionais quando da definição e contratação da sede olímpica.

\section{Financiamento}

A unidade temática relativa ao financiamento dos Jogos Olímpicos de 2016 engloba o conjunto de registros que tratam dos recursos alocados direta e indiretamente no planejamento e desenvolvimento da candidatura do Rio de Janeiro à sede olímpica.

O apoio à candidatura do Brasil aos Jogos de 2016 inclui até o pagamento de vestuário para a equipe que entregará o dossiê de candidatura na Suíça. Um dos últimos convênios assinados entre o Ministério do Esporte e o COB (Comitê Olímpico Brasileiro) prevê o custeio da viagem da comitiva que irá à sede do Comitê Olímpico Internacional - a data final de entrega é 12 de fevereiro. O valor ultrapassa $\mathrm{R} \$ 273$ mil e inclui gastos com passagens aéreas e ferroviárias, hospedagens, aluguel de vans, vestuário e serviços fotográficos (BIANCONI; LAJOLO, 2009, n.p.). 
Cabe ressaltar que o total dos gastos necessários à realização dos Jogos, conforme os registros apontam, corresponde apenas a estimativas. O orçamento flexível, aliás, conforme aponta Preuss (2008) é uma marca na organização de megaeventos esportivos, o que pode ser comprovado pelo próprio Pan 2007.

Especificamente sobre campanha de candidatura do Rio de Janeiro a cidade sede, foram gastos $\mathrm{R} \$ 138$ milhões. Mais uma vez foi o fundo público a fonte da maior parte dos recursos, $\mathrm{R} \$ 101$ milhões. $\mathrm{O}$ restante, veio da iniciativa privada, $\mathrm{R} \$ 37$ milhões, patrocinados pelo Bradesco, Odebrecht, TAM, Embratel e Grupo EBX. Proni (2004) demonstra que o êxito da edição dos Jogos de 1992 em Barcelona e o insucesso dos Jogos de 1996 em Atlanta ratificaram a certeza de que os Jogos Olímpicos não concebem mais um modelo de financiamento baseado unicamente nos investimentos advindos da iniciativa privada. O esgotamento de um modelo pautado no investimento privado, cobrando cada vez mais o financiamento público, é produto do crescimento dos Jogos Olímpicos promovido como um grande e lucrativo negócio.

Por conseguinte, a incapacidade dos investidores privados em sustentar a realização dos Jogos significou uma participação cada vez maior dos Estados nacionais. Segundo PRONI (2004, p. 14), a fórmula atual se configura pela seguinte expressão: "o organizador paga a festa, mas não o local da festa". Para a conquista e organização dos Jogos, o Estado de se responsabilizar pelos investimentos urbanos para capacitar a cidade-sede a abrigar os Jogos, ao passo que a venda de ingressos e espaços de publicidade, os direitos de imagem e o licenciamento de produtos devem cobrir os gastos com o evento esportivo propriamente dito. No entanto, no Brasil, essa separação assume outros contornos, no qual o governo tem financiado inclusive áreas pelas quais não seria inicialmente responsável.

O BNDES (Banco Nacional de Desenvolvimento Econômico e Social) vai ser o principal financiador das duas maiores competições esportivas do mundo, a Copa de 2014 e a Olimpíada do Rio, em 2016. O banco deve oferecer ao menos R\$ 15 bilhões para os eventos. Mais do que bancar diretamente os custos das empreitadas bilionárias, o governo federal vai passar ao BNDES a tarefa de custear com empréstimos os principais 
gastos de infraestrutura urbana, os mais custosos, para os dois eventos (GOMIDE, 2009, n.p.).

De acordo com Salvador (2010), o orçamento público constitui mais do que uma mera peça técnica de estrutura contábil, uma vez que é capaz de refletir a correlação de forças sociais e os interesses envolvidos na apropriação dos recursos públicos, ao mesmo tempo, expressa a definição de quem vai arcar com o ônus do financiamento dos gastos públicos. Nesse sentido, depreendemos que o delineamento das fontes de financiamento pode, igualmente, acenar quais são os atores e os interesses que hegemonizam a busca de um determinado país pelo direito a sediar os Jogos Olímpicos

\section{Conclusão}

Vários temas ficam em aberto: o cenário de concorrência interurbana fazendo da cidade uma espécie de empresa que concorre no mercado com outras cidades empresa; a opinião pública favorável à realização dos Jogos, o que reflete o investimento simbólico para legitimação do projeto; a história do Movimento Olímpico contada sob a lógica do entretenimento, com destaque para os heróis e seus feitos, os fatos marcantes e curiosidades; o delicado tema da segurança pública, o que envolve a ação militar e as políticas focalizadas voltadas à pacificação das favelas e manejo social do risco imposto ao projeto; os enormes investimentos em infraestrutura realizados, com seus impactos para planejamento territorial urbano; as medidas de exceção para garantia do poder monopolista exercido pelo COI sobre os negócios envolvendo a marcas produtos e imagem dos Jogos; o incremento do turismo e a construção da imagem do Rio como cidade global, boa para viver, visitar e, principalmente, consumir.

Por agora, podemos concluir que o projeto Rio 2016 está articulado com o projeto mais geral de desenvolvimento nacional. Queremos dizer com isso que o modelo econômico em curso e a política externa de reposicionamento do país na geopolítica mundial são aspectos fundantes da candidatura olímpica carioca. Neste contexto, não é de se estranhar uma política esportiva cujo objetivo passa pela projeção do país à condição de potência olímpica, revitalizando, assim, os discursos de massificação do esporte por meio da escola. Programas e ações governamentais voltados ao esporte escolar se combinam ainda 
à diversificação dos investimentos em direção a esportes com maior distribuição de medalhas, outra tendência anunciada.

Sobre os investimentos e financiamento, embora predominem a crítica e as denúncias envolvendo a gestão do esporte olímpico brasileiro, o que se evidencia pelo exemplo do Pan de 2007, o Estado é que vai se responsabilizar pela maior parte dos custos de organização dos Jogos. De todo modo, ainda que o financiamento seja público, é política do COI ter participação ativa na execução do projeto, com seu próprio plano geral de organização. Isto porque a evolução do marketing olímpico transformou o evento esportivo Jogos Olímpicos num megaevento empresarial.

Como se percebe a agenda de pesquisas sobre os temas e termos do debate que perpassam o agendamento dos Jogos Rio 2016 é abrangente e desafiadora. Isto significa problematizar não os temas aqui identificados e abordados, mas vários outros possíveis. Em tempos de megaeventos, será preciso um grande esforço da comunidade acadêmica no sentido de questionar os interesses e projetos hegemônicos que se articulam a partir do esporte e, também, para a Educação Física.

\title{
RIO 2016 GAMES'S SCHEDULE: TERMS AND TOPICS FOR DISCUSSI- ON
}

\begin{abstract}
The training schedule comprises a turning point in public policy formulation, defining objects of government intervention. In this sense, we analyzed the terms and themes that go through the scheduling of 2016 Games. The research was based on documentary survey constructed from institutional sources and printed media, discussed with technical support in the content analysis. Allowed to map the interests which permeated Rio bid to host the Olympics, to identify trends in Brazilian sports policy and discuss the public-private relationship in the context of organizing the Games, as well as identifying challenges for the research agenda on sports mega-events.
\end{abstract}

Keywords: Public policy. Public-Private Partnership. Sports.

\section{EL AGENDAMIENTO DE JUEGOS RIO 2016: TEMAS Y TÉRMINOS PA- RA EL DEBATE}

\section{Resumen}

La formación de la agenda consta de un punto de inflexión en la formulación de políticas públicas y la definición de los objetos de la intervención del gobierno. En este sentido, se analizan los temas y las condiciones del agendamiento de los Jue- 
gos Rio 2016. La investigación se basa en el estudio documental construido a partir de fuentes institucionales y medios de comunicación impresos, discutido con el apoyo técnico en el análisis de contenido. Fue posible mapear los intereses que permean la candidatura de Río para albergar los Juegos Olímpicos, para identificar las tendencias en la política deportiva brasileña y discutir las relaciones públicoprivadas en el contexto de la organización de los Juegos, así como la identificación de desafíos para la agenda de investigación en megaeventos deportivos.

Palabras clave: Políticas Públicas. Participación Público-Privada. Deportes.

\section{Referências}

ALMEIDA, P. R. Uma política externa engajada: a diplomacia do governo Lula. Revista Brasileira de Política Internacional, Brasília, v. 47, n. 1, p. 162-184, jan./jun., 2004.

ANTUNES, C. Euforia com Brasil é excessiva, mas parte de fenômenos globais. Folha de S. Paulo, São Paulo, 30 dez. 2009. Disponível em: <http://www1.folha.uol.com.br/fsp/especial/fj3012200906.htm>. Acesso em: 25 jun. 2010. Não paginado.

BARDIN, L. Análise de conteúdo. 4. ed. Lisboa: Edições 70, 2010.

BIANCONI, G.; LAJOLO, M. Ministério gasta até com roupas da Rio-2016”. Folha de S. Paulo, São Paulo, 09 jan. 2009. Disponível em: <http://www1.folha.uol.com.br/fsp/esporte/fk0901200902.htm>. Acesso em: 23 jun. 2009.

BRASIL. Ministério do Esporte. III Conferência Nacional do Esporte: texto básico. Brasília: [s.n.], 2010a.

Resoluções da III Conferência Nacional do Esporte. Brasília: [s.n.], 2010b. Disponível em: http://portal.esporte.gov.br/conferencianacional/resolucoesIIICNE.jsp. Acesso em: 5 set. 2010.

Assessoria de Comunicação do Ministério do Esporte. Deodoro abrigará atletas com potencial olímpico do projeto Brasil Vale Ouro. Ministério do Esporte, Brasília, 7 jul. 2009. Disponível em: < http://www.esporte.gov.br/ascom/noticiaDetalhe.jsp?idnoticia $=5630>$. Acesso em: 05 set. 2010. Não paginado.

Governo federal reúne equipe responsável pela Candidatura Rio 2016. Ministério do Esporte, Brasília, 10 dez. 2008. Disponível

em: 
$<$ http://www.esporte.gov.br/ascom/noticiaDetalhe.jsp?idnoticia $=5335>$. Acesso em: 05 set. 2010. Não paginado.

BRACHT, V.; ALMEIDA, F. Q. A política de esporte escolar no Brasil: a pseudovalorização da Educação Física. Revista Brasileira de Ciências do Esporte, Campinas, v. 24, n. 3, p. 87-101, maio, 2003.

COMITÊ OLÍMPICO BRASILEIRO. Programa Time Brasil e Time Rio. Disponível em: < http://timebrasil.cob.org.br/>. Acesso em: 13 set. 2010.

COMITÊ RIO 2016. Rio 2016: cidade candidata. Dossiê de candidatura. Rio de Janeiro: COB, 2009.

CRUZ, L.; BASTOS, M. Com a Olimpíada, Brasil pode superar viralatice. Folha de S. Paulo, São Paulo, 4 out. 2009. Disponível em: $<$ http://www1.folha.uol.com.br/fsp/esporte/fk0410200910.htm>. Acesso em: 03 set. 2010.

FOLHA DE S. PAULO. Plano é barato em relação à verba do Brasil. Folha S. Paulo, São Paulo, 16 fev. 2010. Disponível em: < http://www1.folha.uol.com.br/fsp/esporte/fk1602201020.htm>. Acesso em: 7 set. 2010a. Não paginado.

. TCU aponta mais irregularidades no Pan, e Congresso cria Ato Olímpico. Folha de S. Paulo, São Paulo, 18 jun. 2009a. Disponível em: $\quad<$ http://www1.folha.uol.com.br/fsp/esporte/fk1806200934.htm>. Acesso em: 5 set. 2010. Não paginado.

. Ex-lanterna, Rio cresce e iguala jogo por 2016. Folha de S. Paulo, São Paulo, 3 set. 2009b. Disponível em: <http://www1.folha.uol.com.br/folha/esporte/ult92u618692.shtml>. Acesso em: 23 nov. 2009. Não paginado.

. Brasil edita sua campanha até o final. Folha de S. Paulo, São Paulo, 3 out. 2009c. Disponível em: <http://www1.folha.uol.com.br/fsp/especial/fj0310200907.htm>. Acesso em: 5 set. 2010. Não paginado.

. Campanha já consumiu R \$ 138 mi. Folha de S. Paulo, São $\overline{\text { Paulo, }} 2$ out. 2009d. Disponível em: <http://www1.fo- 
lha.uol.com.br/fsp/esporte/fk0210200931.htm>. Acesso em: 9 set. 2010. Não paginado.

FRANCO, M. L. P. B. Análise de conteúdo. 2. ed. Brasília: Liber Livro, 2005.

GOMIDE, R. BNDES assume Copa e Olimpíada. Folha de S. Paulo, São Paulo, 06 out. 2009. Disponível em: <http://www1.folha.uol.com.br/fsp/esporte/fk0610200911.htm>. Acesso em: 25 jun. 2010. Não paginado.

HARVEY, David. A produção capitalista do espaço. 2. ed. São Paulo: Annablume, 2006.

ITOKAZU, F. Brasil quer ter 8 tenistas no top 40 até 2016. Folha S. Paulo, São Paulo, 12 fev. 2010. Disponível em: <http://www1.folha.uol.com.br/fsp/esporte/fk1202201012.htm>. Acesso em: 8 set. 2010. Não paginado.

MARTINS, J. E. Erros do Pan deixaram lições para os Jogos de 2016. Folha de S. Paulo, São Paulo, 5 out. 2009. Disponível em: $<$ http://www1.folha.uol.com.br/fsp/esporte/fk0510200941.htm>. Acesso em: 7 jul. 2010. Não paginado.

MASCARENHAS, F. et al. O bloco olímpico: Estado, organização esportiva e mercado na configuração da agenda Rio 2016. [S.I.: s.n.], 2011.

MATTOS, R. Nas mãos de Nuzman. Folha de S. Paulo, São Paulo, 29 jul. 2010. Disponível em: < http://wwwl.folha.uol.com.br/fsp/esporte/fk2907201015.htm>. Acesso em: 8 set. 2010. Não paginado.

MELO, M. P. Esporte e Juventude Pobre: políticas públicas de lazer na Vila Olímpica da Maré. Campinas: Autores Associados, 2005.

PREUSS, H. Impactos econômicos e megaeventos: copa do mundo de futebol e jogos olímpicos. In: RODRIGUES, R. P. et al. (Orgs.). Legados de megaeventos esportivos. Brasília: Ministério do Esporte, 2008. p. 79-90.

PRONI, M. W. Marketing e organização esportiva: elementos para 
uma história recente do esporte-espetáculo. Conexões, Campinas, v. 1, n. 1, p. 82-94, jul/dez., 1998

. A metamorfose dos Jogos Olímpicos (1896-1996). In: ENCONTRO REGIONAL DE HISTÓRIA, 17., 2004, Campinas. Anais... Campinas: [s.n.], 2004.

RANGEL, Sérgio. Autoridade Olímpica terá formato de consórcio. Folha de S. Paulo, São Paulo, 19 mar. 2010. Disponível em: $<$ http://www1.folha.uol.com.br/fsp/esporte/fk1903201014.htm >. Acesso em: 3 set. 2010.

SALVADOR, E. Fundo público e seguridade social no Brasil. São Paulo: Cortez, 2010.

SÁNCHEZ, F. et al. A cidade olímpica como construção política e simbólica: notas sobre o projeto Rio 2016. In: INTERNATIONAL CONFERENCE MEGA-EVENTS AND THE CITY, 2010, Niterói. Anais... Niterói: [s.n.], 2010.

TAVARES, O. Quem são os vencedores e os perdedores dos Jogos Olímpicos? Pensar a Prática, Goiânia, v. 8, n. 1, p. 69-84, jan./jun., 2005.

TORRES, Sérgio. Pan registrou caso de irregularidade e fiscalização frouxa. Folha de S. Paulo, São Paulo, 3 out. 2009. Disponível em: $<$ http://www1.folha.uol.com.br/fsp/especial/fj0310200922.htm>. Acesso em: 9 set. 2010.

VILLANO, B.; TERRA, R. Definindo a temática de Legados de Megaevento Esportivos. In: RODRIGUES, R. P. et al (Orgs.). Legados de megaeventos esportivos. Brasília: Ministério do Esporte, 2008.

VAINER, C. Rio 2016: um jogo (Olímpico?) de cartas marcadas. Jornal dos Economistas, Rio de Janeiro, n. 245, p. 3-4, dez., 2009.

. Megaeventos e cidade de exceção. In: INTERNATIONAL CONFERENCE MEGA-EVENTS AND THE CITY, 2010, Niterói. Anais... Niterói: [s.n.], 2010. 
Recebido em: 09/07/2012

Revisado em: 19/09/2012

Aprovado em: 05/11/2012

\section{Endereço para correspondência}

fernandom@unb.br

Fernando Mascarenhas

Universidade de Brasília, Faculdade de Educação Física.

Campus Universitário Darcy Ribeiro

Asa Norte

70910-900 - Brasilia, DF - Brasil 